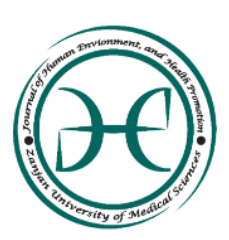

Journal of Human, Environment and Health Promotion

Journal homepage: www.zums.ac.ir/jhehp

\title{
Investigating the Relationship between Employee Safe Behavior and Safety Culture in a Livestock Industry
}

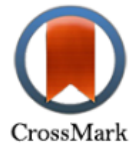

\author{
Shirazeh Arghami a,*, Fateme Taghizade ${ }^{a}$ \\ ${ }^{a}$ Department of Occupational Health Engineering, School of Public Health, Zanjan University of Medical \\ Sciences, Zanjan, Iran.
}

*Corresponding author. E-mail address: arghami@ zums.ac.ir

\section{A R T I C L E I N F O}

Article history:

Received March 11, 2017

Accepted April 29, 2017

Article Type:

Original Article

Keywords:

Safety Culture

Unsafe Behavior

Safety Behavior Sampling

Livestock Industry

\begin{abstract}
A B S T RA C T
Background: Occupational incidents still account for a high percentage of causes of death and disability. A study was designed to determine the relationship between employee safe behavior and safety culture.

Methods: In this analytical study, all employees of an industrial livestock units of Tehran participated $(n=200)$. The data on the employee behavior was evaluated using the safety sampling technique based on the ANSI Dangerous Acts List (Modified Form). A standard questionnaire was used to assess the safety culture. Data were analyzed by the SPSS software, at the significance level of 0.05 .

Results: The mean safety score of people (138) was acceptable. The rate of unsafe behaviors was $35 \%$. The most unsafe behaviors were due to improper manual handling $(83 \%)$. A reverse correlation between unsafe behavior and safety culture score (P value $=$ $0.001)$ was seen.

Conclusion: The results of this study indicate that there is a significant negative reciprocal relationship between safety culture and unsafe behavior, that is, with the increase in the safety culture, the rate of unsafe behavior decreases. As a result, by promoting the level of safety culture, the rate of unsafe behavior can be reduced.
\end{abstract}

\section{Introduction}

Occupational incidents still account for a high percentage of deaths and disabilities [1]. The study of the International Labor Organization shows that the share of employees' vulnerability in Central Asia is $32.8 \%$, which is three times more than the share of employees in developed countries [2].

Therefore, it is necessary for study in these countries is more urgent.

Traditionally, it has been emphasized that employee are the cause of more than $90 \%$ occupational injuries. However, the new approach has shifted to organizational causes [1]. As today, hardware and software attitudes in the control of incidents have been heavily influenced by the bio ware approach [3]. This means that it is not possible to establish safe behaviors in the industrialized society by imposing safety laws and regulations. Instead, we should reduce incidents at work through the creation of a positive and

To cite: Arghami SH, Taghizade F. Investigating the Relationship between Employee Safe Behavior and Safety Culture in a Livestock Industry. J Hum Environ Health Promot. 2017; 2(3):193-198. 
effective safety culture [4]. Studies in recent years also show that the management system and safety culture have a significant role to play in safety and incident statistics [5]. The term "safety culture" was first introduced in 1987 in the Nuclear Agency's report on the Chernobyl catastrophe.

Subsequently, numerous questions about major incidents were raised about deficiencies in organizational structure and safety management systems [6]. So far, various definitions have been made for the safety culture, but the concept of all of them is to understand individuals from the hazardous conditions and their behavioral background in responding to those conditions. For example, we can say that a safety culture is a complex structure that incorporates the attitudes, values and behaviors of the members of the organization that are able to change and interact with the actual behavior of the incident.

Given that attitudes and values are not observable, the assessment of the safety culture is mainly based on the questionnaire. By using such questionnaires, the level of safety culture in the organization, as well as, the main factors that need to be strengthened can be identified. So far, various theories about the relationship between safety culture and incidents have been presented.

But the frequency of incidents is not as large as to check such a relation. Instead, it is possible to examine the relationship between safety culture and safe behavior [6]. Fortunately, behaviors are observable, and their observation produces objective data. In addition, the ultimate goal of safety culture is to create in-person safety behaviors.

One of the common methods for monitoring safe behaviors is Safety Behavior Sampling. This technique is conducted in observance based on safety regulations and the application of the established probability rules [9], and the implementation requires the use of an unsafe list of actions. An unsafe behavior is meant to behave beyond the standard and defined limits of the system and can affect the level of safety of the system [10]. Although such studies have been conducted in other countries, and such a link has been identified [6], however; in Iran there is little report on such studies. Mentioned above, a study was designed to determine the relationship between employee's safe behavior and safety culture in a livestock industry.

\section{Materials and Methods}

This research is a descriptive-analytic study on which the employees of a livestock industry participated in an overwhelming number $(\mathrm{n}=$ 200). Prior to the study, the informed consents were obtained. In addition to demographic characteristics registration questionnaire, two methods were used to collect other data .

Data of workers' act were collected by a safety sampling method. In this study, a list of unsafe acts that had prepared by the American National Standards Institute (ANSI) was used. The list from ANSI had a general attitude and considered general conditions of the industry. Thus, the list was revised and modified according to the type and nature of the work, the instructions, and the reports of workplace accidents. Then, the information was recorded by referring to the workplace and observing employee behavior. All observations were made from $8 \mathrm{AM}$ to $4 \mathrm{PM}$ and were subtle. To record the desired behavior, we tried to consider the minimum time to observe, because behavior can change at the moment [10].

Finally, unsafe behaviors were expressed in percentage.

A cut off point of $50 \%$ was considered to determine the status of employee's behavior.

Therefore, if the ratio of unsafe behaviors was more than 50 percent, it was considered as unfavorable condition. As the same way, from 50 to 25 percent was considered relatively favorable, and less than $25 \%$ was considered desirable.

A standard Iranian questionnaire was used to assess the safety culture. The questionnaire has 42 questions that examine the safety culture in five dimensions, including: management commitment, the level of information exchange, training, safety of the work environment and safety priority. In another study, the validity and reliability of this 
questionnaire were determined [12]. The questionnaire was provided to the staff in person and a described how to complete it. Scoring questionnaire was based on the Likert 5 point scale (strongly disagree, disagree, no idea, agree, and strongly agree), which respectively the belonged score was 1-5. In this questionnaire, negatively charged items (representing inappropriate conditions) are reversely scored. In the order that their score is reduced to 6 and then entered into the analysis. To determine the status of the safety culture on situations, the cutting point was considered to be $50 \%$ (equal to 126 points).

Therefore, if the score was less than 126, it was considered as undesirable safety culture. From 126 to 168 was considered relatively favorable, and more than 168 was considered desirable. Collected data was analyzed by SPSS software version 11 .

For this purpose, $\mathrm{t}$ test, Pearson correlation test and regression were used at the significant level of 0.05 .

\section{Results and Discussion}

Data analysis indicated that the mean age of the study group was $33 \pm 8.2$ years and the average work experience of the staff was $5 \pm 2.1$ years. A high percentage of them (97\%) was married and more than one third $(35.5 \%)$ had a sub-diploma degree.

In order to investigate the behavior of employees, close to 25,000 observations were made, indicating that 35 percent of the behaviors of individuals were unsafe behaviors.

The most insignificant recorded behavior was due to improper manual handling $(83 \%)$.

The lowest recorded unsafe behavior related to the high speed of milk trucks and avoiding the use of safety devices, as well as, horse playing. Each of these three behaviors accounted for $0.5 \%$ of the set of unsafe behaviors.

To study the effect of level of education on unsafe behavior, one-way analysis of variance was used and it was found that there is a significant relationship between the level of education and unsafe behavior $(\mathrm{P}$ value $=0.04)$. The effect of work history and age on unsafe behavior were examined by Pearson correlation test (Table 1).

The test showed no significant correlation between work experience and unsafe behavior $(\mathrm{P}$ value $=0.89)$. But there was a significant relationship between age and unsafe behavior $(\mathrm{P}$ value $=0.05$ ).

The analysis of safety culture questionnaire data showed that the average safety employee's grade of the industry was 138. Therefore, the safety culture of the employees of this industry can be considered as relatively favorable.

One-way analysis of variance was used to evaluate the effect of level of education. The results showed that there was a significant relationship between education level and safety culture score $(\mathrm{P}$ value $=0.05)$.

There is no significant correlation between work experience $(\mathrm{P}$ value $=0.15)$ and safety culture. But there is a significant correlation between age and safety culture $(\mathrm{P}$ value $=0.04)$ (Table 1).

Table 1: The relationship between some demographic characteristics, unsafe behavior and safety culture.

\begin{tabular}{lccc}
\hline Demographic & $\begin{array}{c}\text { Age } \\
\text { (P value) }\end{array}$ & $\begin{array}{c}\text { Education } \\
\text { level } \\
\text { (P value) }\end{array}$ & $\begin{array}{c}\text { Work } \\
\text { experience } \\
\text { (P value) }\end{array}$ \\
\hline Unsafe behavior & 0.05 & 0.04 & 0.89 \\
Safety culture & 0.04 & 0.05 & 0.15 \\
\hline
\end{tabular}

The final section of the findings, which is the main purpose of the present study, was to examine the relationship between the safety culture and the behavior of the employees of the studied industry.

The results showed that by increasing the safety culture score, the level of unsafe behaviors decreases. The results of regression test showed a significant reverse correlation between unsafe behavior and safety culture score $(\mathrm{P}$ value $=$ 0.001). By increasing the unsafe behaviors, the 
safety culture score has decreased and vice versa

(Fig. 1).

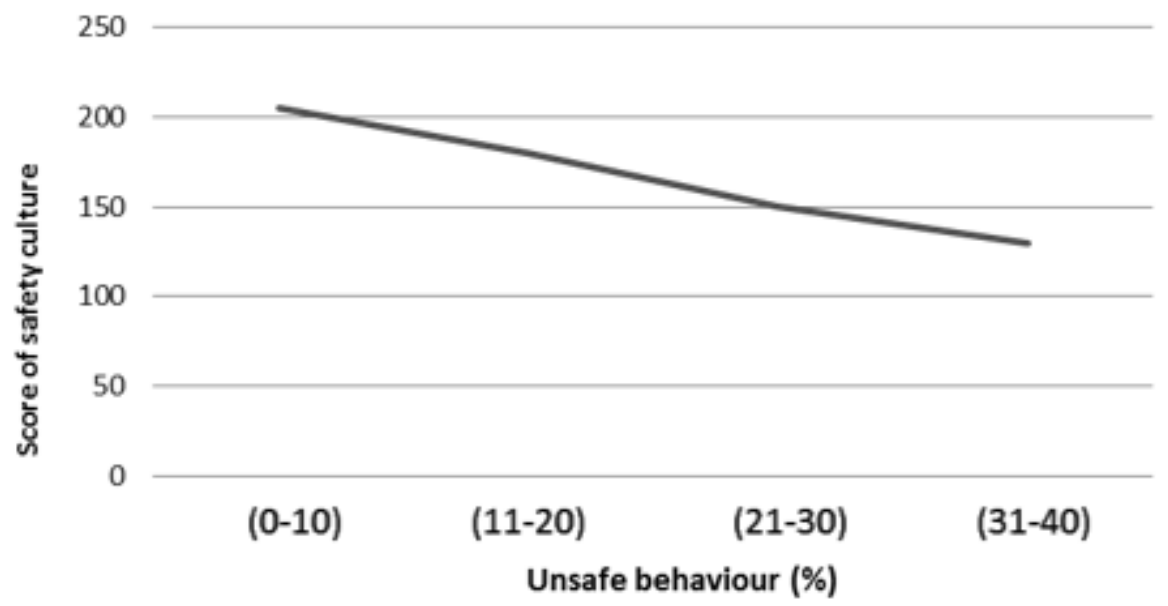

Fig. 1: The relationship between safety culture and unsafe behavior.

This study was conducted in a livestock industry in Tehran with the aim of determining the relation between safety culture and unsafe behavior. The findings showed that the mean score of the safety culture of the employees was fairly favorable (138) and approximately 35\% of the observed behaviors were unsafe. The most significant unsafe behavior measured was improper manual handling, with 83 percent of the employees repeating this unsafe behavior. Other studies have also shown that this behavior is overwhelming. One can mention the study of Mohammadfam et al. (2008). In the recent study, the improper manual handling with a frequency of $90 \%$ is considered the most frequent unsafe behavior, after standing under the suspended load (98\%) [13]. Also, Surrey et al. (2013) showed that this behavior is one of the most frequent behaviors of employees [14]. After improper manual handling, the most frequent unsafe behavior was avoiding the use personal protective equipment $(56 \%)$. This finding is consistent with the results of many other studies, including the study of Arghami et al. (2009) in the construction industry [3], the study of Nuri et al (2008) in Iran Gas Company [15], and Hasheminjhad et al. (2012) Kermanshah oil refinery [16].

In both cases that the increased education can be effective in improving behaviors. Although the attitude towards predictive safety is one of the perilous behaviors of a person [17], in the study of Samsi et al. (2013), it was found that a favorable attitude of employees is not consistent with doing good behavior [18].Therefore, in addition to training, one should not forget the role of attitude. Moreover, the likelihood of the effects of these measures on the safety culture score cannot be ignored.

The results of this study showed the importance of the level of education in safe behaviors. The present study indicates that there is a significant relationship between education and unsafe behavior $(\mathrm{P}$ value $=0.04)$. This result is consistent with the results of the study of Heydari et al. (2004) at the oil refinery, Mohammadfam et al. (2008) in a car company [18 and 19]. The results of this study indicated that safety culture, as well as the rate of unsafe behaviors has a significant relationship with the educational level $(\mathrm{P}$ value $=$ $.05)$, which is consistent with the results of the study by Mohammadfam et al. (2010) in the metalworking industry [19].The reason for this can be attributed to the impact of the level of education on people's safety attitudes. In fact, it seems as if the higher the level of education is, it may strengthen the attitude of the individual towards safety. Although the importance of education in promoting the social aspects of life is clear; these findings will be another reason. 
Statistical analysis showed that there was a significant relationship between unsafe behaviors and age, as well as between safety culture and age.

This finding is also consistent with the findings of the study by Mohammadfam [19] and the study of Taghdisi et al. (2013) in one of the oil refineries [20]. Perhaps it can be concluded that by age, people become more cautious and modify their unsafe behaviors.

There was no significant relationship between work experience and unsafe behavior $(\mathrm{P}$ value $=$ $0.89)$ and safety culture score $(\mathrm{P}$ value $=0.15)$. The result is not consistent with most of the studies, such as Hasheminejad et al. (2012), which was carried out on workers at the Kermanshah Oil Refinery [16]. It is likely that this relationship in the present study can be regarded as a small work experience in the industry (average $\pm 2,1 \pm 5$ years).

\section{Conclusion}

The results indicate a reverse relationship between unsafe behavior and safety culture. That is, with the increase in the safety culture, the rate of unsafe behavior decreases. In the study of Nasirpour et al. (2012), it was found that a safety culture and immune function have a positive relationship [21]. In the studies abroad, the positive relationship has also been reported. For example, Zhang et al. (2011) achieved the same result in one of the coal mines in China [22]. In high-tech industries, the same results was confirmed [6]. Also in small places such as a dorm, the importance of management supervision was shown [23].

According to the above, it should be noted that the promotion of the level of safety culture and the safe behavior of employees are interlinked. It means that improving in system and safety management cause to enhance safe behaviors. On the other hand, by enhancing safe behavior (training and monitoring), can promote safety culture.

\section{References}

1. Goh YM, Love PE, Stagbouer G, Annesley C. Dynamics of Safety Performance and Culture: A Group Model Building Approach. Accid Anal Prev. 2012; 48:118-25.

2. International Labour Organization. Global Employment Trends Update. Geneva: ILO; 2009: 25.

3. Arghami Sh, Yousefi-Aghcand M. Methods of Behavior Based Safety Assessment. The $1^{\text {th }}$ International Conference on Petrochemical (IPC). Tehran: Petrochem Res Technology Company. 2008.

4. Shekari M, Shirali G, Hosseinzadeh T. Safety Culture Assessment among Laboratory Personnel of a Petrochemical Company. J Health Saf Work. 2014; 4(1): 65-72.

5. Toori G, Mazloumi A, Hosseini M. Developing a Safety Culture Questionnaire Based on a Customized Modeling in a Car Manufacturing Industry in Iran. J Health Saf Work. 2013; 3(1): 29-38.

6. Morrow SL, Koves GK, Barnes VE. Exploring the Relationship between Safety Culture and Safety Performance in Us Nuclear Power Operations. Saf Sci. 2014; 69: 37-47.

7. Ooshaksaraie M, Amran ABM, Samudi YM, Yahaya. R. Safety Culture Evaluation in the Metal Products Industry of Iran. Eur J Soc Sci. 2009; 11(1): 160-9.

8. Wu T.C, Lin C.H, Shiau S.Y. Developing Measures for Assessing the Causality of Safety Culture in a Petrochemical Industry. Water Air Soil Pollut. 2009; 9(5-6): 507-15.

9. Raouf A, Dhillon BS. Safety Assessment: A Quantitative Approach. Lewis Publishers; 1994.

10. Arghami Sh, Pouya Kian M, Mohammadfam I. Effects of Safety Signs on the Modification of Unsafe Behaviours. Zanjan Univ Med Sci J. 2009; 17(68): 93-8. 
11. Reber RA, Wallin JA. Validation of Behavioral Measure of Occupational Safety. J Organ Behav Manage. 1983; 5(2): 69-78.

12. Nouri Parkestani H, Alimohammadi I, Arghami Sh, Ghohari MR, Farshad AA. Assessment of Reliability and Validity of a New Safety Culture Questionnaire. Iran Occup Health J. 2010; 7(1): 18- 25.

13. Mohammadfam H, Bahrami A, Fatemi F, Golmohammadi R, Mahjub H. Evaluation of the Relationship between Job Stress and Unsafe Acts with Occupational Accidents in a Vehicle Manufacturing Plant. Hamadan Univ Med Sci J. 2008; 15(3): 60-6.

14. Soori H, Mortazavi M, Shahesmaeil A, Mohseni H, Zagiabadi M, Ainy E. Determination of Workers' Risky Behaviours Associated with Safety and Health in a Car Manufacturing Company in 2011. Arak Med Univ J. 2013; 16(3): 54- 61.

15. Nouri J, Azadeh A, Fam IM. The Evaluation of Safety Behaviors in a Gas Treatment Company in Iran. J Loss Prev Process Ind. 2008; 21(3): 31925.

16. Hashemi Nejad N, Mohammad Fam I, Jafari Nodoshan R, Dortaj Rabori E, Kakaei H. Assessment of Unsafe Behavior Types by Safety Behavior Sampling Method in Oil Refinery Workers in 2009 and Suggestions for Control. Occup Med Quart J. 2012; 4(1): 25-33.

17. Malekpour F, Mohammadian Y, Malekpour A, Salimi S, Sarkari A. Study of Relationship between Personality, Attitudes to Safety and Risky Behavior among Motorcycle Drivers in Tehran City. J Health Saf Work. 2012; 2(2): 61-8.

18. Shamsi M, Shams M, Nilipour Tabatabaei A. Attitude and Behaviors Related to Using Personal Protective Equipments: Audience Analysis to Design a Behavior Change Intervention for Employees in Constructing Underground Stations in Esfahan. Iran Occup Health J. 2013; 10(3): 208.
19. Mohammadfam I, Neazamodini Z. Effect of Technical Intervention in Promoting Safety Culture Assessment. Jundishapur J Health Sci. 2010; 2(2): 66-74.

20. Taghdisi MH, Alimohammadi I, Zarie F, Yekefalah D. Assessment Health, Safety \& Environment Culture in an Oil Refinery Based On Geller Model. Iran J Health Educ Health Promot. 2013; 1(3): 47-56.

21. Nassiripour A, Nikoomaram H, Ghafari F, Tajedini M. The Relationship between Organizational Culture and Personnel HSE Performance in a Production Company: A Case Study in Saipa Car Company. J Health Saf Work. 2012; 2(3): 71-84.

22. Jiang-Shi Z, Shu-Shan G, Jia T, Pan-Pan H. Study on Unsafe Behavior Pre-control Method Based on Accidents Statistic. Procedia Eng. 2011; 26: 1964-9 .

23. Arghami S, Kamali K, Mahboubi M. Development of a Fire Safety Checklist for Dormitories. J Hum Environ Health Promot. 2016; 2(1): 20-31. 